\title{
Information Processing of Health Warning \\ Messages on Cigarette Packs Among Young Iranian Smokers: An Application of Elaboration Likelihood Model
}

\section{Fatemeh Shahi}

Tabriz University of Medical Sciences Faculty of Health and Nutrition

\section{Sara Pourrazavi}

Tabriz University of Medical Sciences Faculty of Health and Nutrition

Kamiar Kouzekanani

Texas A\&M University Corpus Christi

Mohammad Asghari Jafarabadi

Tabriz University of Medical Sciences Faculty of Health and Nutrition Hamid Allahverdipour ( $\nabla$ allahverdipourh@tbzmed.ac.ir)

Tabriz University of Medical Sciences Faculty of Health and Nutrition https://orcid.org/0000-00033700-6185

\section{Research article}

Keywords: elaboration likelihood model, health warning messages, smoking, processing route

Posted Date: October 13th, 2020

DOI: https://doi.org/10.21203/rs.3.rs-16577/v2

License: (c) (i) This work is licensed under a Creative Commons Attribution 4.0 International License.

Read Full License 


\section{Abstract}

Background: One of the major smoking prevention strategies has been to educate the public and increase people's awareness, using health warning messages. However, many young people continue smoking without paying attention to health risk messages on cigarette packets in Iran. Hence, this study was conducted to examine the processing route of anti-smoking messages and influencing cognitive factors by using the Elaboration Likelihood Model.

Methods: The non-probability sample for the cross-sectional study consisted of 387 smokers in the age range of 18 to 30 years old in Tabriz, Iran. A researcher-designed questionnaire was used for the purpose of data collection. No causal inferences were drawn due to the non-experimental nature of the study.

Results: It was found that smokers often processed warning messages through the central route. Perceived severity, smoking abstinence self-efficacy, and psychological dependence were predictors of message processing through the central route. The results supported the conceptual model of cognitional predictors of the processing route.

Conclusions: To design and execute effective health warning messages to quit smoking, it is recommended to consider cognitive factors as a means to enhance critical thinking about the content of the message.

\section{Background}

Most smokers start smoking at an early age, when they think there is no need to worry about the side effects of cigarette smoking such as vascular diseases, lung cancer, chronic pulmonary disease, and other head-to-toe side effects (1). According to the literature, smokers tend to underestimate the harmful effects of smoking (2-4); consequently, health policy makers try to persuade smokers to quit smoking by providing appropriate information through effective communication channels (5).

Health warning messages are known to be effective in positively affecting the attitudes of people towards health-related issues (6); for example, on cigarette packages to inform the users of negative consequences of smoking (7), focusing on dangers of tobacco use $(5,8)$. In fact, pictorial health warning labels are regarded as a cost-effective medium and an effective communication method for providing health information among vulnerable groups, increasing awareness, and motivating smokers to quit cigarette smoking (5). Therefore, the content of these messages is important and must make people think about it carefully, if not, it is not taken seriously (9).

According to avoidance-oriented approach, emotions, such as fear, influence people's decision-making process. Therefore, an effective warning message may motivate people to engage in behaviors that protect them from the potential threat (7). In addition to fear, the credibility of the message and its source may influence the warning message's effectiveness (10). According to the Elaboration Likelihood Model (ELM), there are two pathways to influence the creditability and usefulness of the message. 
The ELM, developed by Petty Cacioppo, is a dual process theory, describing the change of attitudes through two major routes to persuasion, namely, central and peripheral routes $(11,12)$. Sometimes people tend to think carefully about the contents of a message based on their knowledge. On the other hand, there are people who are either unwilling or unable to analyze the contents of the message based on a logical manner; thus, peripheral factors, such as how and where the message is delivered and its visual impact, play a prominent role in the emotional pathway. In addition, Petty and Cacioppo assumed that motivation and ability are two influential factors affecting the occurrence of a message $(11,12)$. In fact, attitudinal changes through the central route require the motivation to cognitively process the persuasive message, the ability to process the message, and a predominance of favorable cognitive responses on peripheral factors. On the other hand, such changes through the peripheral route may result if motivation, ability, or positive thinking are not present. Peripheral route change requires that the topic of persuasive communication be associated with favorable cues. According to the ELM, message recipients have various levels of ability, personal interest, and motivation to elaborate the presented content (13). Therefore, those who are highly motivated to quit smoking and have sufficient ability to process the information follow the central route by relying on their knowledge and perceived personal relevance with a message. Whereas, people with lower motivation to quit or lower ability to process the information are likely to process the received message through the peripheral route by relying on superficial cues and less thoughtful evaluation of the information (11).

According to the available literature, there is a strong relationship between information processing and risk perception $(14,15)$. In this regard, researchers suggest people who perceive low health risk are expected to process risk reduction messages differently than do the people who feel vulnerable to the threat (16). For example, Pointer and Rogers (1993) found that perceived severity and vulnerability increase the likelihood of processing through the central route in persuasive communication that recommended moderate alcohol consumption. In fact, they stated that high protection motivation is more likely to lead to central message processing because it increases the perceived personal relevance with threat (16). Alternatively, low protection motivation, because of decreased perceived personal relevance, would process the message in accordance with peripheral cues (16). In addition, issue involvement, temporal busyness, or self-efficacy on the given subject (17-19) may result in a different elaboration likelihood among individuals. Yoo (2017) examined the importance of self-efficacy in determining the message processing route and reported its positive moderating impact on a central route but negative moderating influence on three peripheral routes. High self-efficacy helps people focus their energy on message processing. Familiarity through knowing the relevant subject allows individuals not to be distracted; thus, leading their engagement to deep thinking (20).

Young people believe that the unpleasant consequences of substance abuse occur at an old age and for older people and do not involve them (21). On the other hand, Te'eni-Harari et al. (2007) found that, contradictory to adults, young people are a less intellectually oriented population, who mostly enact based on peripheral route to process information and are less influenced by motivation and ability variables (22). In this regard, in spite of the presence of warning images on cigarette packets about the physical threats of smoking in Iran (23), many young people continue smoking without paying attention 
to health risk messages. Therefore, it may be concluded that message processing is different for young people than older ones. There is a lack of evidence in Iran about how the youth processes the tobaccorelated risk messages. The primary purpose of the study was to evaluate the information processing of health warning messages on cigarette packs in a sample of Iranian youths. The following research questions guided the study: How do smokers process health warnings on cigarette packs? What role do cognitive factors play in determining processing routes?

\section{Methods}

\section{Subject Selection}

The cross-sectional was conducted between July and November of 2018 in Tabriz, Iran with 387 current smokers. To recruit the participants, 10 parks and coffee shops in Tabriz's 10 districts were randomly selected. The sample consisted of the youth who ranged in age from 18 to 30 years, reported being smokers, were not taking any medications for psychiatric disorder, voluntarily agreed to participate in the study, and signed the consent, representing a non-random sample. Data were collected through a selfadministered questionnaire. Cigarette packs with health warning messages, which had been prepared by the research team, were presented to the participants before completing the questionnaires. The Ethics Committee of Tabriz University of Medical Sciences had approved the study.

\section{Instrumentation}

A panel of Seven (7) health psychologists and eight (8) health education and promotion experts examined the content validity of the instrument by rating each questionnaire item for relevance, clarity, representativeness, and essentiality. The means of the content validity index (CVI) and the content validity ratio (CVR) were 0.87 and 0.95 , respectively, attesting to the content validity of the instrument. The instrument was pilot-tested with 50 young smokers to examine its utility.

\section{Demographics}

The demographic variables included age, gender, living arrangement (with parents, personal home, dormitory), marital status (single or married), employment status (full-time, part-time, unemployed), and the highest level of education. Additionally, history of hookah use, alcohol use, drugs abuse, smoking among friends and family members, the number of cigarettes smoked per day, smoking behavior after waking up and the first bidder of cigarette smoking were measured.

\section{Message Processing Route}

For evaluating processing routes of peripheral and central, based on the ELM, we included two most influential factors of "motivation" and "ability". The extent of motivation was determined by the attitude towards the message, personal relevance, and the need for cognition. Additionally, individuals' ability for elaboration was operationalized by "distractions" and "knowledge". In our study, the midpoint of the sum 
of motivation and ability was used to categorize the processing route into the peripheral (less than 2016.65) or central (greater than 2016.65).

The attitude towards the message was measured by 12 items developed by the researchers; for example, "pictures motivated me to reduce my daily number of cigarettes smoked". Additionally, we developed 3item scale to assess perceived relevance; for example, "in my opinion, the pictures on the cigarette packet talked about my health conditions." The need for cognition was measured by the 6-item version of Cacioppo and Petty's (1982) scale that was proposed by Lins de Holanda Coelho et al. $(2018)(24,25)$; for example, "I would prefer complex to simple problems". A 5-point Likert-type scaling ( 1 = extremely uncharacteristic of me, 5 = extremely characteristic of me) was used. Reliability coefficients for the attitude towards the message $(a=0.92)$, perceived relevance $(a=0.82)$, and need for cognition $(a=0.71)$, attested to the internal consistency of the scale scores.

Additionally, ability was measured by knowledge and distractions, utilizing two scales that were developed by the research team. Specifically, an 8-item scale was used to measure the knowledge about the potential negative consequences of smoking cigarettes; for example, "smoking can cause lung cancer." Responses were coded as $0=$ no/don't know or $1=$ yes. A 4 -item scale was used to gauge distractions, utilizing a 4-point Likert-type scaling ( 1 = never, 4 = always); for example, "presence of people around me caused to lose my focus on pictures and smoking outcomes." The reliability coefficients for the knowledge and distractions were 0.67 and 0.62 , respectively.

\section{Cognitive Variables}

Perceived severity. To measure the seriousness of smoking risks, Harris's four-item scale of perceptions of personal risk about smoking and health was employed (26); for example, "smokers live shorter lives than non-smokers" and "smoking increases your chance of getting lung cancer". The reliability coefficient for the scale was 0.75 .

Sensation-Seeking. A published 8-item questionnaire was used to assess sensation-seeking behavior (27); for example, "I would like to explore strange places". The estimated reliability coefficient was 0.82 .

Psychological dependence. A four-item scale, derived from Autonomy Over Smoking scale (28) was used to measure psychological dependence; for example, "I rely on smoking to focus my attention" and "I rely on smoking to take my mind off being bored." The reliability coefficient for the scale was 0.80 .

Smoking abstinence self-efficacy. A 12-item instrument (SASEQ) was used to assess self-efficacy (29); for example, "you feel very sad, are you confident that you will not smoke?" The reliability coefficient for this scale was 0.80 .

Positive attitude toward smoking. A 9- item researcher-made instrument was used to gauge participants' attitude toward smoking; for example, "smoking makes me look attractive" and "smoking makes me feel independent." The reliability coefficient for the scale was 0.67 . 
Cognition reaction. A 5- item researcher-made scale, which was based on a published study (29) was used to gauge the cognitive response that participants felt after seeing the images; for example, "I felt scared after seeing my pictures." The reliability coefficient for the scale was 0.76 .

With the exception of ability, we used a 5-point Likert-type scaling ( $1=$ the lowest, $5=$ the highest) to measure the abovementioned scales. For the purpose of the SEM, all were standardized, ranging from 0 to 100 .

\section{Health Warning Messages on Cigarette Packs}

The research team developed four (4) health warning messages to stick on cigarette packs that were pictorial in nature, because they are known to be more effective than are the text warnings (29). Given that health warning messages that emphasize the physical consequences of a threat are helpful in informing and encouraging people to engage in preventive health behavior (30), we used images related to smoking-related (e.g., cancers of the respiratory system, mouth, and teeth, Buerger's disease).

\section{Data Analysis}

To analyze the data, the Statistical Package for the Social Sciences (SPSS), version 23, and Mplus software, version 6, were used. Descriptive statistics, Mean (SD) and frequency (\%), were used to summarize the data. The respondents' responses to the questionnaire items were used to measure each scale score. The normality of all distributions was examined by skew and kurtosis indices. A series of Chisquare Test of Independence was performed to examine the simple associations between the processing route and demographic characteristics. To compare the cognitive constructs scores in processing routes, a series of independent sample t-test was applied. The significance level for all analyses was set, a priori, at 0.05 .

Applying the Mplus software, we performed structural equation modeling (SEM), with maximum likelihood estimation, to test the hypothesized model for cognitive predictors of the processing route in full sample (Model A) and gender groups (Model B). The SEM included model specification, identification, estimation, testing, and modification. The first step focused on the conceptual model regarding the hypotheses. The second step consisted of the model fit process, wherein the number of input and output parameters were suitably chosen. The maximum likelihood estimation was performed in the third step. The fit indices were assessed in the fourth step. In the fifth step, the modification indices were used to modify the model. Model fit measures were attained to judge how well the proposed model captured the covariances between all measures. Since the quality of fitted models is influenced by the sample size, multiple model fit indices were estimated, which were as follows: $\chi 2(p>0.05), \chi 2 /$ degrees of freedom < 5 , the Root Mean Square Error of Approximation (RMSEA $\leq$ 0.08), the Standardized Root Mean Square Residual (SRMR $\leq 0.05)$, the Comparative Fit Index (CFI $\geq 0.90)$, and Tucker-Lewis index (TLI $\geq 0.90)$ (31).

\section{Results}


The majority of the participants (57.40\%) processed the message through the central route, of which, $80.00 \%$ were female, $73.10 \%$ lived with their families, $69.40 \%$ smoke one cigarette per day, and $72.90 \%$ reported the first cigarette offered by their friends. Whereas $40.10 \%$ who processed the message with peripheral route were male, $47.00 \%$ lived in a dormitory, $56.80 \%$ smoked more than 15 cigarettes per day, and $58.80 \%$ reported the first cigarette offered by nobody. As shown in Table 1, a series of the Chi-square Test of Independence showed a statistically significant difference in processing route by gender, residency status, smoking rate, and the first bidder of using a cigarette.

As can be seen in Table 2, mean differences between the central and peripheral routes were statistically significant based on the positive attitudes towards smoking (favoring the peripheral route), while central route scored higher on smoking abstinence self-efficacy, perceived severity, and psychological dependence. Sensation seeking did not distinguish between the two routes.

The respondents were provided with four distraction items: (1) presence of other people at their side distracting their attention to warning images; (2) not paying attention to risk message images on cigarette packs when doing other things; (3) becoming worried by the pictures on the cigarette packets; and (4) the severity of the thirst for smoking. As shown, "frequently" was the option endorsed the most by all subjects in general and those employing the central route in particular.

The respondents were provided with five cognition reaction items: (1) thinking to quit smoking after seeing picture on cigarette packets; (2) thinking to reduce smoking after seeing pictures on cigarette packets; (3) being attracted by picture on cigarette packets; (4) being reminded of the dangers of smoking after seeing pictures on cigarette packets; and (5) being scared by seeing pictures of self. As can be seen Table 4, the majority of those who processed the messages via the peripheral route disagreed or strongly disagreed with all items. On the other hand, central route processors agreed or strongly agreed with all items.

A series of SEM was performed to test the hypothesized model for cognitive predictors of the processing route. Model $A$ is depicted in Figure 1 and shows the predictors among young smokers. The measurement model resulted in a good model fit $\left(X^{2}=71.78, n=387, d f=5, p<0.05, C F I=1.00, T L I=1.00\right.$, RMSEA $=$ $0.00, \mathrm{Cl}: 0.00,0.05)$. The direct associations between self-efficacy, perceived severity, psychological dependence as predictor of the central route were statistically significant. The association between sensation seeking and the had central route was not statistically significant. Moreover, results indicated a statistically significant direct relation between attitude toward smoking and peripheral route. The following prediction equation was obtained: Message Processing Route $=4.398-0.001 \times$ Attitude +0.056 $\times$ Self-efficacy $+0.113 \times$ Perceived Severity $+0.010 \times$ Sensation Seeking $+0.055 \times$ Psychological Dependence, in which, 1-unit increase in attitude results in 0.001 decrease in message processing route. Additionally, 1-unit increase in self-efficacy, perceived severity, sensation seeing, and psychological dependence results in $0.056,0.113,0.010$, and 0.055 increase in message processing route, respectively. 
Next, we evaluated Model B for males and females separately and found that the conceptual model obtained from testing the goodness of fit causal structure of the hypothesized model fit the data well ( $\chi 2$ $=0.00, \mathrm{n}=387, \mathrm{df}=0, \mathrm{p}<0.05, \mathrm{CFI}=1.00, \mathrm{TLI}=1.00, \mathrm{RMSEA}=0.00(\mathrm{Cl}: 0.00,0.05)$. Among males and with respect to central route, the negative association with the attitude toward smoking and positive relations with self-efficacy, perceived severity, and psychological dependence were statistically significant. Among females, the positive associations between self-efficacy and perceived severity as predictors of the central route were statistically significant. Results are depicted in Figures 2 and 3.

The prediction equation for the males, Message Processing Route $=4.145-0.002 \times$ Attitude $+0.058 \times$ Self-efficacy $+0.084 \times$ Perceived Severity $+0.019 \times$ Sensation Seeking $+0.061 \times$ Psychological Dependence, shows that 1 -unit increase in attitude results in 0.002 decrease in message processing route, while 1-unit increase in self-efficacy, perceived severity, sensation seeking, and psychological dependence results in $0.058,0.084,0.019$, and 0.061 increase in message processing route, respectively.

The prediction equation for the females, Message Processing Route $=4.145-0.001 \times$ Attitude $+0.052 \times$ Self-efficacy $+0.101 \times$ Perceived Severity $-0.008 \times$ Sensation Seeking $+0.056 \times$ Psychological Dependence, shows that 1-unit increase in attitude and sensation seeking results in 0.001 and 0.008 decrease in message processing route, respectively, and 1-unit increase in self-efficacy, perceived severity, and psychological dependence results in $0.052,0.101$, and 0.056 increase in message processing route, respectively.

\section{Discussion}

The young smokers in our study often processed warning messages through the central route. According to the Elaboration Likelihood Model (ELM), message processing depends on one's motivation and ability (11); thus, if people have high motivation and ability, they process messages centrally, if not, it is probably accomplished peripherally or sensationally (32-35). Since motivation depends on factors such as the attitude, need for cognition, personal relevance to the subject, and the ability of being conscious and focused (36), it can be concluded that observing images was instrumental in raising awareness/ knowledge and creating a sense of concern among the study's participants. In fact, they were thinking that these consequences were relevant to their smoking behavior. Consequently, despite the tendency to smoke, it was assumed that the study subjects processed messages through central rout and based on the ELM. Our review of the literature also showed that warning images in cigarette packages increase people's awareness about the negative impact of smoking, which eventually raises individuals' concerns about their health, thereby, provoking the attention to the importance of quitting tobacco smoking (37-43). Additionally, warning images may increase the attention and remind smokers of adverse effects of tobacco smoking.

We found that perceived severity, smoking abstinence self-efficacy, and psychological dependence were strong predictors of message processing through the central route. It is postulated that the perceived severity refers to one's belief that smoking can have serious and unpleasant consequences for his or her 
health (44) and numerous studies have shown that anti-tobacco warning images may increase people's fear perception and improve awareness of smokers about the side effects of tobacco use, thereby, being exposed to these messages may motivate smokers to quit smoking $(37,45-49)$. In addition, Muñoz, Chebat, and Borges (2013) believed that graphic warnings have the potential to increase the sense of being worried about adverse consequences and influence individuals' attention and intention toward stopping cigarette smoking (50). Muñoz and his colleagues also found that these warnings messages can lead to an in-depth information processing and that focusing on graphic warning messages may provoke people to not engage in this high risk behaviors $(7,50)$. Moreover, it seems that due to the visual clarity of illustrations about the seriousness of the damages caused by smoking, smokers may relate the health risk messages to themselves and perhaps process the message through central route, which was reported in a study about AIDS warning messages (16).

Another factor that was found to be associated with processing via central manner is psychological dependence, which postulates that an addicted person, for example, drinks or smokes to fulfill a need (51). In other words, psychological dependence arises when someone is emotionally tied to tobacco use based on her or his mental desire for it. Our findings showed that cigarette smokers who were psychologically dependent on cigarettes and were exposed to fear appeals images, they processed the scary images in a logical manner. In fact, challenges about the side effects of cigarette smoking in the mind of a smoker on one hand and psychological dependence, caused by consistent and frequent exposure to smoking and smoking-related behaviors and dependency (52), on the other hand, may explain why one does not try to quit smoking. It seems that although addicted people process the warning messages via central route, because of psychological dependence, they are unable to quit smoking or drinking. This paradox may be explained by the ELM and other theoretical frameworks, that is, why someone who processes the messages correctly via a central route, still continues its use? Thus, future studies must be conducted to provide an answer. And it seems that the ELM works better in persuasive programs, where there is no psychological dependence for quitting behavior.

Although it is assumed that high sensation-seeking people process messages through peripheral or emotional rout, we found no support for it in our study. Sensation-seeking is a personal condition; for example, wanting to experience a new thing, but without thinking about its consequences (53).This feeling develops at the age range of 10 to 15 years and reaches its peak at around of the age of 20 (5456). Young people with high levels of sensation-seeking have a high risk-taking ability to experience physical, social, and legal risks, exhibit less protective beliefs about risky behaviors, and underestimate the severity of the risks $(53,57)$. High sensation seekers typically do not perceive the fear of threatening situations. As a result, they do not perceive high-risk behaviors, such as, smoking, alcohol, and drug abuse as threatening behaviors $(51,58-64)$. It has also been reported that sensation-seeking could act as a predictor of response to a fearful condition, which may provoke a response to "fear control" that ultimately results in a defensive avoidance behavior in case of being exposed to fearful messages (65) . Therefore, it seems that people with high levels of sensation-seeking are not attentive to the negative consequences of smoking presented in the delivered messages. In addition, they do not try to process the messages, because they find them irrelevant to themselves. Furthermore, in accordance with the extended 
parallel process model, maybe these individuals enter the fear control process and reject the message with a defensive avoidance response.

Some studies have suggested that females pay more attention to warning messages than do males (66, $67)$. However, others have found the same result in males $(68,69)$. We found that females and males process warning messages about cigarette smoking differently but in a logical manner. For example, females are more likely to process messages through the central route than do males. The structural equation modelling of the data showed that psychological dependence predicts the processing of warning messages through central route only among men. It seems psychological dependence on cigarette smoking shifts females toward peripheral route. Thus, gender differences must be taken into consideration in designing and implementing relevant messages.

Repetition of message could be one of the factors which is related to the ability to think and enables more people to think in a logical manner. Hence in case of presenting a strong argument, repetition of message probably leads to more change in beliefs. Additionally, quality of argument may have an influential role in interventional studies conducted within the framework of the Elaboration Likelihood Model (70).

Moreover, it is postulated that individuals distinguish strong and weak arguments only if they are able to process the message in a systematic manner. In other words, reading a message containing strong arguments will be accepted easily in comparison to messages containing weak arguments. As a result, if someone does not process the message systematically, it may not be able to distinguish strong and weak arguments; thus, argument would be unqualified. Based on this reasoning, the presence or absence of an effect of argument quality on acceptance of the message, indicates how people process the message systematically or not $(11,71)$.

\section{Limitations}

The non-experimental study was cross-sectional; thus, no causal inferences were drawn. Due to nonprobability nature of the sampling technique, the generalizability/external validity of the study was limited to its participants. As in any survey research, providing socially acceptable responses could have been a threat to the internal validity of the results. To mitigate this possibility, respondents were assured at the start of the survey that all responses would be kept confidential.

\section{Conclusion}

Our non-probability sample of young Iranian tobacco smokers showed that they tend to process health warning messages through the central route, and pictorial health warning labels have the potential to encourage people to reduce or quit smoking with a logical approach. It seems that people who are addicted to smoking are insightful and understand the side effects of tobacco use but because of their dependency on nicotine, they cannot cease it. In other words, despite understanding the consequences of tobacco use and process the message through the central route, they cannot cease it. However, non- 
smokers probably process the health warning messages through a different route. Therefore, it is necessary to consider the quality of the arguments, the individuals' awareness of the consequences of smoking, and the repetition of the message in designing the messages in order to change people's attitudes towards smoking. Health officials should pay special attention to the demographic characteristics of smokers in designing health warning messages related to smoking to increase their effectiveness. In addition, we suggest concerned individuals pay attention to messages that may positively impact people's attitudes toward quitting smoking by emphasizing the severity of the damage caused by smoking.

\section{Abbreviations}

ELM

Elaboration Likelihood Model

SASEQ

Smoking Abstinence Self-Efficacy Questionnaire

SEM

Structural Equation Modeling

\section{Declarations}

\section{Ethics approval and consent to participate}

Participants were given an information sheet on details about the research and verbal consent was collected from each participant. Verbal consent was sought to decrease the time burden on participants and increase response rates. This research and approach were reviewed and approved by the Tabriz University of Medical Sciences Institutional Review Board.

\section{Consent for publication}

Not applicable.

\section{Availability of data and materials}

The datasets used and/or analyzed during the current study are available from the corresponding author on reasonable request.

\section{Competing interests}

The authors declare that they have no conflict of interest.

\section{Funding}


This article is part of a Master of Science thesis in health education and promotion, which was supported and approved by Tabriz University of Medical Sciences, Tabriz, Iran. The funders had no role in study design, data collection and analysis, decision to publish, or preparation of the manuscript.

\section{Author contributions}

FSH, SP, and HA designed the study. FSH collected the survey data. FSH, SP, MAJ, and HA analyzed the data. FSH, SP, MAJ, and HA were major contributors in writing the manuscript. KK edited the manuscript. All authors read and approved the final manuscript.

\section{Acknowledgments}

Not applicable.

\section{References}

1. Vasiljevic M, Petrescu D, Pepper J, Ribisl K, Marteau T, editors. WHAT IS THE IMPACT OF ECIGARETTE ADVERTS ON CHILDREN'S PERCEPTIONS OF TOBACCO SMOKING? A RANDOMISED CONTROLLED TRIAL. INTERNATIONAL JOURNAL OF BEHAVIORAL MEDICINE; 2016: SPRINGER 233 SPRING ST, NEW YORK, NY 10013 USA.

2. Hammond D, Fong GT, McNeill A, Borland R, Cummings KM. Effectiveness of cigarette warning labels in informing smokers about the risks of smoking: findings from the International Tobacco Control (ITC) Four Country Survey. Tobacco control. 2006;15(suppl 3):iii19-iii25.

3. Oncken C, McKee S, Krishnan-Sarin S, O'Malley S, Mazure CM. Knowledge and perceived risk of smoking-related conditions: a survey of cigarette smokers. Preventive medicine. 2005;40(6):779-84.

4. Morgan JC, Byron MJ, Baig SA, Stepanov I, Brewer NT. How people think about the chemicals in cigarette smoke: a systematic review. Journal of behavioral medicine. 2017;40(4):553-64.

5. Hammond D. Health warning messages on tobacco products: a review. Tobacco control. 2011;20(5):327-37.

6. McGuire WJ. Attitudes and attitude change. The handbook of social psychology. 1985:233-346.

7. Mutti-Packer S, Collyer B, Hodgins DC. Perceptions of plain packaging and health warning labels for cannabis among young adults: findings from an experimental study. BMC public health. 2018;18(1):1361.

8. Azagba S, Sharaf MF. The effect of graphic cigarette warning labels on smoking behavior: evidence from the Canadian experience. Nicotine \& Tobacco Research. 2012;15(3):708-17.

9. Shanahan P, Elliott D. Evaluation of the effectiveness of the graphic health warnings on tobacco product packaging 2008. Canberra: Australian Government Department of Health and Ageing. 2009.

10. Emery LF, Romer D, Sheerin KM, Jamieson KH, Peters E. Affective and cognitive mediators of the impact of cigarette warning labels. Nicotine \& Tobacco Research. 2013;16(3):263-9. 
11. Petty RE, Cacioppo JT, Schumann D. Central and peripheral routes to advertising effectiveness: The moderating role of involvement. Journal of consumer research. 1983;10(2):135-46.

12. Petty RE, Cacioppo JT. Communication and persuasion: Central and peripheral routes to attitude change: Springer Science \& Business Media; 2012.

13. Petty RE, Cacioppo JT. The elaboration likelihood model of persuasion. Advances in experimental social psychology. 1986;19:123-205.

14. Trumbo CW. Heuristic-systematic information processing and risk judgment. Risk Anal. 1999;19:391400.

15. Trumbo CW. Information processing and risk perception: An adaptation of the Heuristic-Systematic model. J Commun. 2002;52:367-82.

16. Dinoff BL, Kowalski RM. Reducing AIDS risk behavior: The combined efficacy of protection motivation theory and the elaboration likelihood model. Journal of Social and Clinical Psychology. 1999;18(2):223-39.

17. Zhou T. Understanding users' initial trust in mobile banking: An elaboration likelihood perspective. Computers in Human Behavior. 2012;28(4):1518-25.

18. Bhattacherjee A, Sanford C. Influence processes for information technology acceptance: An elaboration likelihood model. MIS quarterly. 2006:805-25.

19. Angst CM, Agarwal R. Adoption of electronic health records in th presence of privay concerns: the elaboration likelihood model and individual persuation. MIS Q. 2009;33:339-70.

20. Yoo CW, Goo J, Huang CD, Nam K, Woo M. Improving travel decision support satisfaction with smart tourism technologies: A framework of tourist elaboration likelihood and self-efficacy. Technological Forecasting and Social Change. 2017;123:330-41.

21. Kosmidou K. The determinants of banks' profits in Greece during the period of EU financial integration. Managerial finance. 2008;34(3):146-59.

22. Te'eni-Harari T, Lampert SI, Lehman-Wilzig S. Information processing of advertising among young people: The elaboration likelihood model as applied to youth. Journal of Advertising Research. 2007;47(3):326-40.

23. Asadian A, Aghamolaei T, Ghanbarnejad A. Attitude And Reaction to Health Warning Message Of Cigarette Packaging On Smokeres. Iranian Journal of Health Education and Health Promotion. 2013;1(2):9-18.

24. Lins de Holanda Coelho G, H. P. Hanel P, J. Wolf L. The Very Efficient Assessment of Need for Cognition: Developing a Six-Item Version. Assessment. 2018:1073191118793208.

25. Cacioppo JT, Petty RE. The need for cognition. Journal of Personality and Social Psychology. 1982;42:116-31.

26. Harris JK, Karamehic-Muratovic A, Herbers SH, Moreland-Russell S, Cheskin R, Lindberg KA. Perceptions of personal risk about smoking and health among Bosnian refugees living in the United States. Journal of immigrant and minority health. 2012;14(3):413-9. 
27. Hoyle RH, Stephenson MT, Palmgreen P, Lorch EP, Donohew RL. Reliability and validity of a brief measure of sensation seeking. Personality and Individual Differences. 2002;32(3):401-14.

28. DiFranza JR, Wellman RJ, Ursprung W, Sabiston C. The Autonomy Over Smoking Scale. Psychology of Addictive Behaviors. 2009;23(4):656.

29. Spek V, Lemmens F, Chatrou M, van Kempen S, Pouwer F, Pop V. Development of a smoking abstinence self-efficacy questionnaire. International journal of behavioral medicine. 2013;20(3):4449.

30. Witte K, Meyer G, Martell D. Effective health risk messages: A step-by-step guide. Thousand Oaks: CA: Sage; 2001.

31. Weston R, Gore Jr PA. A brief guide to structural equation modeling. The counseling psychologist. 2006;34(5):719-51.

32. Petty RE, DeSteno D, Rucker DD. The role of affect in attitude change. 2001.

33. Petty RE, Fabrigar LR, Wegener DT. Emotional factors in attitudes and persuasion. Handbook of affective sciences. 2003;752:772.

34. Flynn BS, Worden JK, Bunn JY, Connolly SW, Dorwaldt AL. Evaluation of smoking prevention television messages based on the elaboration likelihood model. Health education research. 2011;26(6):976-87.

35. Li C-Y. Persuasive messages on information system acceptance: A theoretical extension of elaboration likelihood model and social influence theory. Computers in Human Behavior. 2013;29(1):264-75.

36. Petty RE, Kasmer JA, Haugtvedt CP, Cacioppo JT. Source and message factors in persuasion: A reply to Stiff's critique of the Elaboration Likelihood Model. 1987.

37. Miller CL, Quester PG, Hill DJ, Hiller JE. Smokers' recall of Australian graphic cigarette packet warnings \& awareness of associated health effects, 2005-2008. BMC Public Health. 2011;11(1):238.

38. Thrasher JF, Pérez-Hernández R, Arillo-Santillán E, Barrientos-Gutiérrez I. Towards informed tobacco consumption in Mexico: effect of pictorial warning labels in smokers. Salud publica de Mexico. 2012;54(3):242-53.

39. Wilson N, Weerasekera D, Hoek J, Li J, Edwards R. Increased smoker recognition of a national quitline number following introduction of improved pack warnings: ITC Project New Zealand. Nicotine \& Tobacco Research. 2010;12(suppl_1):S72-S7.

40. Fong G, Cameron R, Brown K. Effects of the Canadian graphic warning labels among high school students: a quasi-experimental longitudinal survey. Presentation at the 2002 National Conference on Tobacco or Health, San Francisco, California, 20 November 2002. 2002.

41. Elliott P, Shanahan S. Evaluation of the health warnings and explanatory health messages on tobacco products. Research report prepared for Commonwealth Department of Health and Aged Care ...; 2000. 
42. O’Hegarty M, Pederson LL, Nelson D, Wortley P, Yenokyan G. Peer Reviewed: Young Adults' Perceptions of Cigarette Warning Labels in the United States and Canada. Preventing Chronic Disease. 2007;4(2).

43. Devlin E, Anderson S, Hastings G, Macfadyen L. Targeting smokers via tobacco product labelling: opportunities and challenges for Pan European health promotion. Health Promotion International. 2005;20(1):41-9.

44. Glanz K, Rimer BK, Viswanath K. Health Behavior and Health Education: Theory, Research, and Practice 4th Edition. Jossey-Bass publisher; 2008.

45. Brown A, Moodie C. Adolescents' perceptions of tobacco control measures in the United Kingdom. Health Promotion Practice. 2012;13(1):41-7.

46. Drovandi A, Teague P-A, Glass B, Malau-Aduli B. A systematic review of smoker and non-smoker perceptions of visually unappealing cigarette sticks. Tobacco induced diseases. 2018;16.

47. Wang A-L, Lowen SB, Romer D, Giorno M, Langleben DD. Emotional reaction facilitates the brain and behavioural impact of graphic cigarette warning labels in smokers. Tobacco control. 2015;24(3):22532.

48. Floyd DL, Prentice-Dunn S, Rogers RW. A meta-analysis of research on protection motivation theory. Journal of applied social psychology. 2000;30(2):407-29.

49. Evans AT, Peters E, Shoben AB, Meilleur LR, Klein EG, Tompkins MK, et al. Cigarette graphic warning labels are not created equal: They can increase or decrease smokers' quit intentions relative to textonly warnings. Nicotine \& Tobacco Research. 2016;19(10):1155-62.

50. Muñoz Y, Chebat JC, Borges A. Graphic gambling warnings: how they affect emotions, cognitive responses and attitude change. Journal of gambling studies. 2013;29(3):507-24.

51. Kopp M, Wolf M, Ruedl G, Burtscher M. Differences in sensation seeking between alpine skiers, snowboarders and ski tourers. Journal of sports science \& medicine. 2016;15(1):11.

52. Guillaumin C, Urban T. The fight against smoking. The need to consider behavioral dependence. Revue de pneumologie clinique. 2017;73(6):294-8.

53. Zuckerman M. Sensation seeking and risky behavior: American Psychological Association Washington, DC; 2007.

54. Roth M, Schumacher J, Brähler E. Sensation seeking in the community: Sex, age and sociodemographic comparisons on a representative German population sample. Personality and Individual Differences. 2005;39(7):1261-71.

55. Steinberg L, Albert D, Cauffman E, Banich M, Graham S, Woolard J. Age differences in sensation seeking and impulsivity as indexed by behavior and self-report: evidence for a dual systems model. Developmental psychology. 2008;44(6):1764.

56. Srivastava S, John OP, Gosling SD, Potter J. Development of personality in early and middle adulthood: Set like plaster or persistent change? Journal of personality and social psychology. 2003;84(5):1041. 
57. Zuckerman M. Sensation seeking and sports. Personality and individual differences. 1983.

58. Stephenson MT, Hoyle RH, Palmgreen P, Slater MD. Brief measures of sensation seeking for screening and large-scale surveys. Drug and alcohol dependence. 2003;72(3):279-86.

59. Donohew L. Effects of drug abuse message styles: Final report. Report prepared for the National Institute on Drug Abuse. 1988.

60. Keall MD, Newstead S. Analysis of factors that increase motorcycle rider risk compared to car driver risk. Accident Analysis \& Prevention. 2012;49:23-9.

61. Franken RE, Gibson KJ, Rowland GL. Sensation seeking and the tendency to view the world as threatening. Personality and Individual Differences. 1992;13(1):31-8.

62. Smorti M, Guarnieri S. Sensation seeking, parental bond, and risky driving in adolescence: Some relationships, matter more to girls than boys. Safety science. 2014;70:172-9.

63. Hassan HM, Abdel-Aty MA. Exploring the safety implications of young drivers' behavior, attitudes and perceptions. Accident Analysis \& Prevention. 2013;50:361-70.

64. Hassan T, Vinodkumar M, Vinod N. Role of sensation seeking and attitudes as mediators between age of driver and risky driving of powered two wheelers. Journal of safety research. 2017;62:209-15.

65. Blanton H, Snyder LB, Strauts E, Larson JG. Effect of graphic cigarette warnings on smoking intentions in young adults. PloS one. 2014;9(5):e96315.

66. O'Hegarty M, Pederson LL, Nelson DE, Mowery P, Gable JM, Wortley P. Reactions of young adult smokers to warning labels on cigarette packages. American journal of preventive medicine. 2006;30(6):467-73.

67. Koval JJ, Aubut J-AL, Pederson LL, O'Hegarty M, Chan SS. The potential effectiveness of warning labels on cigarette packages. Canadian Journal of Public Health. 2005;96(5):353-6.

68. Omar M, Lajis, R., Foong, K., Sirirassamee, B., Sethaput, C., Borland, R., Fong, G.T., Hammond, D., Thompson, M.E., Driezen, P. \& Elton-Marshall. Proceedings of the 13th World Conference on Tobacco OR Health, Washington DC, USA,. 2006.

69. Willemsen M, Simons C, Zeeman G. Impact of the new EU health warnings on the Dutch quit line. Tobacco control. 2002;11(4):381-2.

70. Eagly AH, Chaiken S. The psychology of attitudes. Fort Worth TX: Harcourt Brace Jovanovich.; 1993.

71. Burnkrant RE, Howard DJ. Effects of the use of introductory rhetorical questions versus statements on information processing. Journal of Personality and Social Psychology. 1984;47(6):1218-30.

\section{Tables}

Table 1: A Summary of Message Processing Routes by Demographic Characteristics ( $n=387)$. 


\begin{tabular}{|c|c|c|c|}
\hline & \multicolumn{2}{|l|}{ Processing Rout } & \\
\hline & Peripheral $(n=129)$ & Central $(n=258)$ & \\
\hline & $\mathrm{N}(\%)$ & $\mathrm{N}(\%)$ & \\
\hline \multicolumn{4}{|l|}{ Gender } \\
\hline Female & $26(20.0)$ & $104(80.0)$ & \multirow[t]{2}{*}{$\mathrm{X}^{2}: 15.61, \mathrm{p}<0.05$} \\
\hline Male & $103(40.1)$ & $154(59.9)$ & \\
\hline \multicolumn{3}{|l|}{ Marital status } & \multirow{3}{*}{$\mathrm{X}^{2}=2.01, \mathrm{p}=0.19$} \\
\hline Married & 97 (35.5) & $176(64.5)$ & \\
\hline Single & $32(28.1)$ & $82(71.9)$ & \\
\hline \multicolumn{3}{|l|}{ Residency status } & \multirow{4}{*}{$\mathrm{X}^{2}: 14.26, \mathrm{p}<0.05$} \\
\hline With family & 59 (26.9) & $160(73.1)$ & \\
\hline Alone & $15(29.4)$ & $36(70.6)$ & \\
\hline In dormitory & $55(47.0)$ & $62(53.0)$ & \\
\hline \multicolumn{3}{|l|}{ Education level } & \multirow{4}{*}{$X^{2}: 0.67, p=0.71$} \\
\hline Elementary education & $12(40.0)$ & $18(60.0)$ & \\
\hline High school education & $28(33.3)$ & $56(66.7)$ & \\
\hline University education & 89 (32.6) & $184(67.4)$ & \\
\hline \multicolumn{3}{|l|}{ Employment status } & \multirow{4}{*}{$X^{2}: 0.23, p=0.89$} \\
\hline Full time & $36(31.6)$ & $78(68.4)$ & \\
\hline Part time & 29 (33.7) & $573(66.3)$ & \\
\hline Unemployed & $64(34.21)$ & $123(65.8)$ & \\
\hline History of hookah use & $105(34.0)$ & $204(66.0)$ & $\mathrm{X}^{2}: 0.29, \mathrm{p}=0.69$ \\
\hline History of alcohol use & $74(35.7)$ & $133(64.3)$ & $\mathrm{X}^{2}: 1.17, \mathrm{p}=0.33$ \\
\hline History of drugs abuse & $31(43.1)$ & $41(56.9)$ & $X^{2}: 3.76, p=0.07$ \\
\hline History of smoking in parents & $66(35.5)$ & $120(64.5)$ & $\mathrm{X}^{2}: 0.74, \mathrm{p}=0.39$ \\
\hline History of smoking in siblings & $48(27.9)$ & $124(72.1)$ & $\mathrm{X}^{2}: 4.10, \mathrm{p}=0.05$ \\
\hline History of smoking in friends & $114(36.0)$ & $203(64.0)$ & $\mathrm{X}^{2}: 5.45, \mathrm{p}<0.05$ \\
\hline \multicolumn{3}{|l|}{ The first bidder of using cigarette } & \multirow{5}{*}{$X^{2}: 21.55, p<0.05$} \\
\hline Friends & $67(27.1)$ & 180(72.9) & \\
\hline Colleagues & $12(32.4)$ & $25(67.6)$ & \\
\hline Relatives & $13(33.3)$ & $26(66.7)$ & \\
\hline Nobody & $37(57.8)$ & $27(42.2)$ & \\
\hline \multicolumn{3}{|l|}{ Smoking Consumption } & \multirow{4}{*}{$X^{2}: 16.19, p<0.05$} \\
\hline 1 cigarette per day & $55(30.6)$ & $125(69.4)$ & \\
\hline 2-15 cigarette per day & 50 (39.7) & $76(60.3)$ & \\
\hline More than 15 cigarette per day & $46(56.8)$ & $35(43.2)$ & \\
\hline \multicolumn{3}{|l|}{ Earliest time to smoke } & \multirow{3}{*}{$\mathrm{X}^{2}: 1.58, \mathrm{p}=0.21$} \\
\hline Immediate after waking up & $64(43.0)$ & $85(57.0)$ & \\
\hline More than 60 minute after waking up & 87 (36.6) & $151(63.4)$ & \\
\hline
\end{tabular}

Table 2: Comparison of Message Processing Routs Based on Cognitive Variables 


\begin{tabular}{llll}
\hline Variable & \multicolumn{2}{c}{ Mean (SD) } & Mean Difference (95\% CI), p-value \\
\cline { 2 - 3 } & Central route & Peripheral route & \\
\hline Smoking abstinence self-efficacy & $40.56(8.46)$ & $33.29(7.96)$ & $-7.27(-8.92,-5.61),<0.05$ \\
Positive attitude toward smoking & $22.67(6.89)$ & $25.04(6.13)$ & $2.36(1.05,3.67),<0.05$ \\
Perceived severity & $16.28(2.84)$ & $13.01(3.17)$ & $-3.26(-3.87,-2.66),<0.05$ \\
Sensation-seeking & $18.34(6.51)$ & $18.92(5.96)$ & $0.57(-0.68,1.83), 0.37$ \\
Psychological dependence & $21.44(5.57)$ & $20.02(5.55)$ & $-1.42(-2.54,-0.29),<0.05$ \\
\hline
\end{tabular}

Table 3: Comparison of Message Processing Routs Based on Distraction Items

\begin{tabular}{|c|c|c|c|}
\hline \multirow[t]{3}{*}{ s } & \multirow{3}{*}{$\begin{array}{l}\text { Answer } \\
\text { choice }\end{array}$} & \multicolumn{2}{|l|}{ Processing Route } \\
\hline & & Peripheral $=129$ & Central $=258$ \\
\hline & & $\mathbf{N}(\%)$ & $\mathbf{N}(\%)$ \\
\hline \multirow[t]{3}{*}{ sresence of people around me caused to lose my focus on pictures and smoking outcomes. } & Never & $37(28.7)$ & $54(20.9)$ \\
\hline & Frequently & $69(53.5)$ & $179(69.4)$ \\
\hline & Always & $23(17.8)$ & $25(9.7)$ \\
\hline \multirow[t]{3}{*}{ I I do something, I cannot focus on pictures and smoking outcomes. } & Never & $35(27.1)$ & $43(16.6)$ \\
\hline & Frequently & $71(55.1)$ & $188(72.9)$ \\
\hline & Always & $23(17.8)$ & $27(10.5)$ \\
\hline \multirow[t]{3}{*}{ jictures on the cigarette packets make me worried and I try to ignore it. } & Never & $58(45.0)$ & $43(16.6)$ \\
\hline & Frequently & $60(46.5)$ & $187(72.5)$ \\
\hline & Always & $11(8.5)$ & $28(10.9)$ \\
\hline \multirow{3}{*}{$\begin{array}{l}\text { :hirst for smoking is so severe in me, so that I ignore the picture on cigarettes packs and } \\
\text { moking consequences. }\end{array}$} & Never & $39(30.2)$ & $56(21.7)$ \\
\hline & Frequently & $68(52.7)$ & $164(63.6)$ \\
\hline & Always & $22(17.1)$ & $38(14.7)$ \\
\hline
\end{tabular}

Table 4: Comparison of Message Processing Routs Based on Cognition Reaction Items 


\begin{tabular}{|c|c|c|c|}
\hline & \multirow[t]{3}{*}{ Answer choice } & \multicolumn{2}{|l|}{ Processing route } \\
\hline & & Peripheral=129 & Central $=258$ \\
\hline & & $\mathbf{N}(\%)$ & $\mathbf{N}(\%)$ \\
\hline \multirow[t]{5}{*}{ to quit smoking after seeing pictures on cigarette packets. } & Strongly agree & $4(3.1)$ & $61(23.6)$ \\
\hline & Agree & $11(8.5)$ & $107(41.5)$ \\
\hline & Undecided & $31(24.1)$ & $42(16.3)$ \\
\hline & Disagree & $59(45.7)$ & $39(15.1)$ \\
\hline & $\begin{array}{l}\text { Strongly } \\
\text { disagree }\end{array}$ & $24(18.6)$ & $9(3.5)$ \\
\hline \multirow{5}{*}{$\begin{array}{l}\text { to reduce smoking after seeing pictures on cigarette } \\
\text { s. }\end{array}$} & Strongly agree & $1(0.78)$ & $41(15.9)$ \\
\hline & Agree & $26(20.16)$ & $133(51.5)$ \\
\hline & Undecided & $28(21.7)$ & $39(15.1)$ \\
\hline & Disagree & $55(42.6)$ & $34(13.2)$ \\
\hline & $\begin{array}{l}\text { Strongly } \\
\text { disagree }\end{array}$ & $19(14.7)$ & $11(4.3)$ \\
\hline \multirow[t]{5}{*}{ stures on the packages attracted my attention. } & Strongly agree & $3(2.3)$ & $44(17.0)$ \\
\hline & Agree & $31(24.0)$ & $139(53.9)$ \\
\hline & Undecided & $36(27.9)$ & $47(18.2)$ \\
\hline & Disagree & $43(33.3)$ & $21(8.1)$ \\
\hline & $\begin{array}{l}\text { Strongly } \\
\text { disagree }\end{array}$ & $16(12.4)$ & $7(2.7)$ \\
\hline \multirow[t]{5}{*}{ :eeing pictures, I remember the dangers of smoking with every time you see a cigar } & Strongly agree & $1(0.78)$ & $37(14.3)$ \\
\hline & Agree & $20(15.5)$ & $117(45.3)$ \\
\hline & Undecided & $32(24.8)$ & $55(21.3)$ \\
\hline & Disagree & $56(43.4)$ & $41(15.9)$ \\
\hline & $\begin{array}{l}\text { Strongly } \\
\text { disagree }\end{array}$ & $20(15.5)$ & $8(3.1)$ \\
\hline \multirow[t]{5}{*}{ cared after seeing my pictures } & Strongly agree & $2(1.6)$ & 45 (17.4) \\
\hline & Agree & $12(9.3)$ & $104(40.3)$ \\
\hline & Undecided & $34(26.4)$ & $67(26.0)$ \\
\hline & Disagree & $59(45.7)$ & $36(14.0)$ \\
\hline & $\begin{array}{l}\text { Strongly } \\
\text { disagree }\end{array}$ & $22(17.0)$ & $6(2.3)$ \\
\hline
\end{tabular}

\section{Figures}




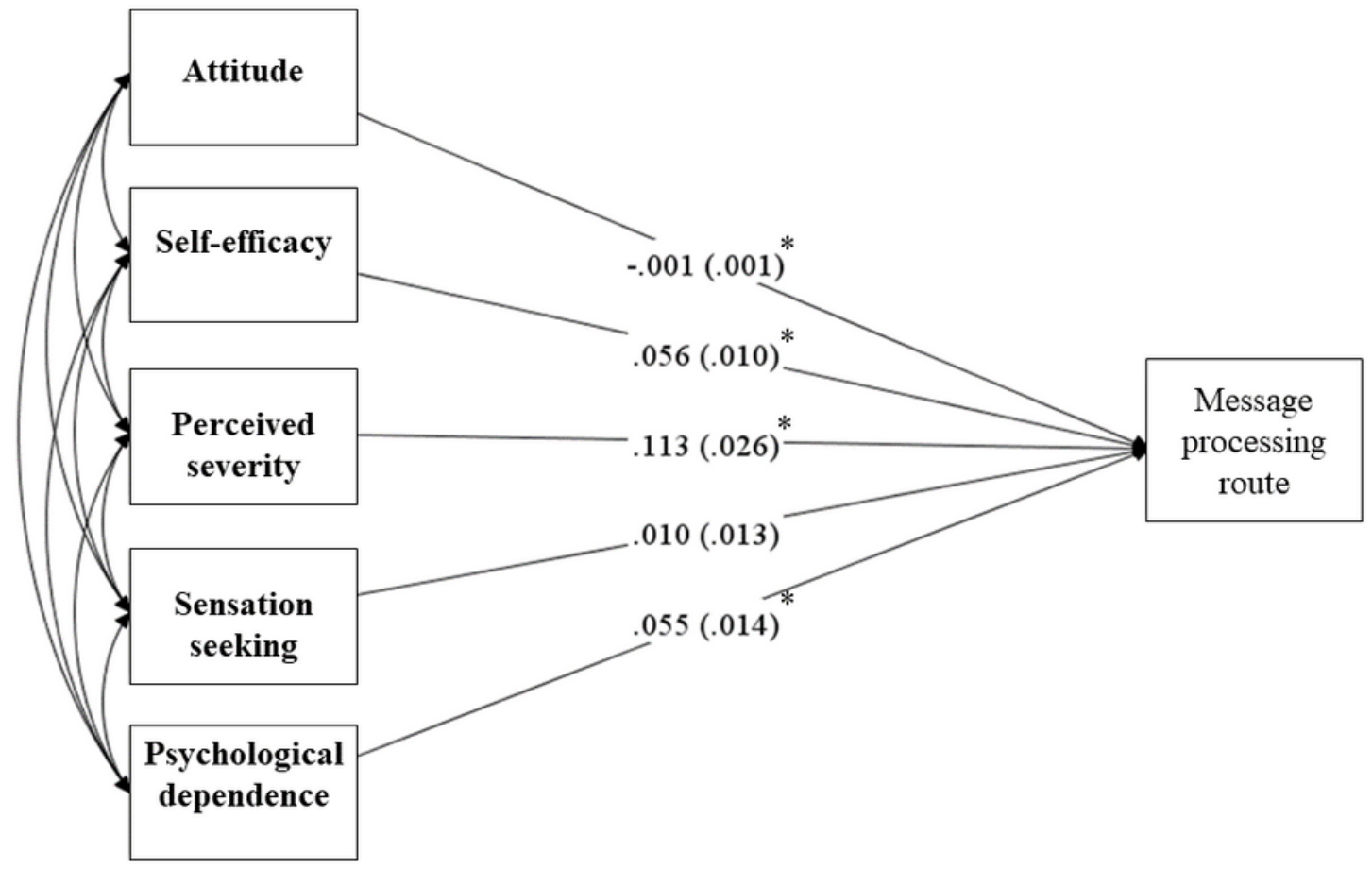

\section{Figure 1}

Structural equation model for the full sample: $\mathrm{CFI}=1.00, \mathrm{RMSEA}=0(90 \%$ confidence interval: $0.00,0.05)$. Parameter values are expressed as maximum likelihood estimates (standardized solution). Numbers in parentheses indicate values for parameter estimates. Message processing route coded as $0=$ peripheral route, 1 = central route. 


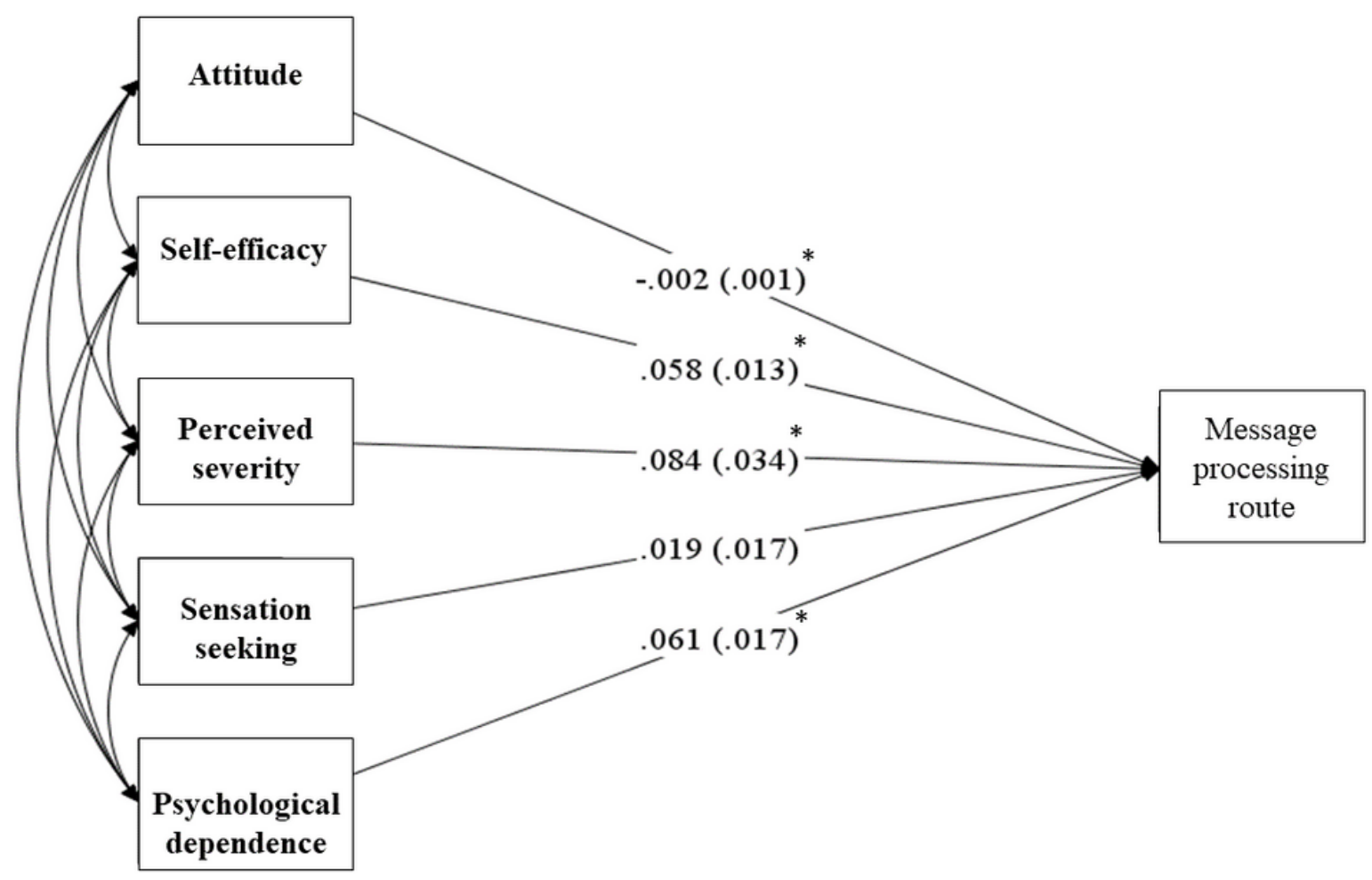

Figure 2

Structural Equation Model B for the male sub-samples: $\mathrm{CFI}=1.00, \mathrm{RMSEA}=0$ ( $90 \%$ confidence interval: $0.00,0.05)$. Parameter values are expressed as maximum likelihood estimates (standardized solution). Numbers in parentheses indicate values for parameter estimates. Message processing route coded as $0=$ peripheral route, 1 = central route. 


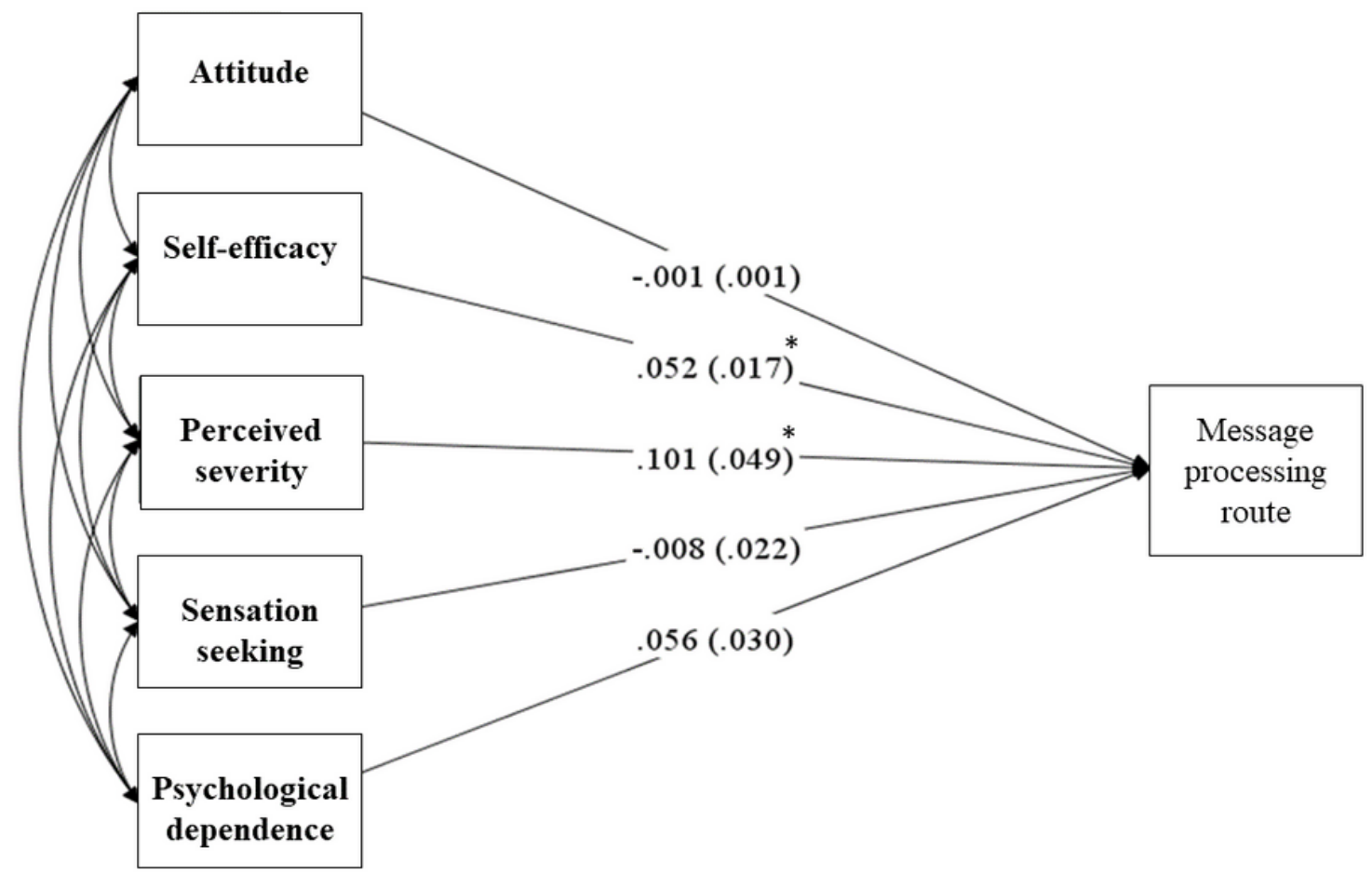

Figure 3

Structural Equation Model B for the female sub-samples: CFI=1.00, RMSEA 0 ( $90 \%$ confidence interval: $0.00,0.05)$. Parameter values are expressed a maximum likelihood estimates (standardized solution). Numbers in parentheses indicate values for parameter estimates. Message processing route coded as $0=$ peripheral route, 1 = central route.

\section{Supplementary Files}

This is a list of supplementary files associated with this preprint. Click to download.

- ElectronicSupplementaryMaterial.doc 